Smoke-free laws

\section{Growing evidence for new benefit of clean indoor air laws: reduced adolescent smoking}

\section{Wakefield, J Forster}

\section{An unexpected benefit of smoke-free laws may be a reduction in smoking among adolescents}

\begin{abstract}
A $s$ the evidence for the risks of harm from exposure to secondhand smoke has grown, so laws and policies to protect workers, children, and other community members from exposure have escalated. Clean indoor air laws are gradually becoming more common, even in traditionally hard to change venues such as restaurants and bars, with countries such as Ireland, Norway, New Zealand, Italy, most Australian states, and a growing number of US states and cities having passed laws eliminating indoor smoking in such venues. While this is good news for protecting the health of nonsmokers, researchers have begun to document another less obvious, but equally welcome, consequence of these changing circumstances in where people can freely smoke.

Until now, only cross sectional research studies had noted a relationship between clean indoor air laws and reduced adolescent smoking. ${ }^{1-3}$ In this issue, Siegel and colleagues report findings from the first longitudinal study to have linked variation in the existence and strength of community level smokefree policies to youth smoking uptake. ${ }^{4}$ They found that youth living in towns with smoke-free restaurant laws that completely banned smoking had lower rates of progression to smoking than those youth living in towns with weaker or no laws. Effects were stronger when smoke-free laws had been in place for longer, and were not explained by a large number of possible individual or community level covariates.
\end{abstract}

\section{INFLUENCE OF BAN ON YOUTH SMOKING}

In terms of criteria for causation, ${ }^{5}$ the advent of clear findings for benefit from this cohort study substantially improves the evidence base that clean indoor air laws can influence youth smoking. Although further cohort studies from different communities or countries would build more confidence in such a conclusion, it is helpful to reflect upon the mechanism or pathway through which such a relationship could occur.

Perhaps more than any other tobacco control strategy, limiting where individuals may smoke in the community substantially changes social norms for tobacco use. Social norms relate to community wide perceptions about acceptable behaviour, as distinct from the more direct (and important) influence of family and friends. With the exception of school policies, laws and policies that create smoke-free environments are primarily designed to regulate the smoking behaviour of adults. Breaking the nexus between freedom to smoke and adulthood may counter the normative association of smoking as an acceptable adult behaviour.

\section{UNRESTRICTED SMOKING}

As suggested by Alesci and colleagues, ${ }^{6}$ unrestricted smoking in public places may influence youth smoking in four ways. First, adults who may freely smoke anywhere increase the amount of negative role modelling to youth. Second, in such environments, youth are presented with more opportunities to smoke. It is well known that smokefree policies limit opportunities for smokers to smoke cigarettes. ${ }^{3}$ Particularly at work, smokers who are subject to smoke-free policies never completely compensate for cigarettes foregone if they had been able to smoke freely. Studies indicate that this applies equally among adolescent workers, limiting the likelihood that low rate opportunistic smoking might consolidate into regular adult smoking. ${ }^{7}$

Third, as a consequence of the second point, unrestricted smoking permits opportunities for social or non-commercial exchange of cigarettes between youth. Studies have shown repeatedly that other adolescents are the most important source of cigarettes for many young smokers, especially the youngest. ${ }^{9}{ }^{10}$ Formal restrictions on where they can smoke as well as social disapproval of smoking in public reduce their opportunities for smoking in groups.

Finally, if smoking is freely permitted, smoking is implicitly communicated to be an acceptable behaviour for members of a society. Consistent with this last point, Alesci et al showed that the more visible smoking is, the more it is perceived by adolescents as socially acceptable and normal. ${ }^{6}$ Thus, clean indoor air laws that include social venues such as restaurants may have indirect influences on youth smoking through substantially influencing the pattern of adult smoking in a community. More generally, measures of tobacco related social norms such as perceived social acceptability of smoking $^{11}$ and perceived smoking prevalence $^{11}{ }^{12}$ have been demonstrated to be significant predictors of adolescent smoking and uptake. Tworek and colleagues have shown that in US states where adult smoking rates are high, adolescent smoking rates are similarly high. $^{13}$

Cross sectional studies also point to beneficial effects on youth smoking of smoking bans in the home ${ }^{28}$ and strongly enforced smoke-free policies at school. ${ }^{214}$ A recent study found that adolescents with a household smoking ban were more likely to perceive lower adult smoking prevalence, and perceive there to be greater disapproval of adult and youth smoking. ${ }^{15}$

The Siegel et al study adds another important argument and more evidence to the already overwhelming case for a ban on smoking in indoor public locations. It also suggests that clean indoor air laws ought to be included in the compendium of evidence based tobacco use prevention methods

Tobacco Control 2005; 14:292-293.

doi: 10.1136/tc.2005.013557

\section{Authors' affiliations}

M Wakefield, Centre for Behavioural Research in Cancer, The Cancer Council Victoria, Australia

J Forster, Division of Epidemiology and Community Health, University of Minnesota, USA

Correspondence to: Dr Melanie Wakefield, Centre for Behavioural Research in Cancer, The Cancer Council Victoria, Australia; melanie. wakefield@cancervic.org.au

\section{REFERENCES}

1 Wasserman J, Manning WG, Newhouse JP, Winkler JD. The effects of excise taxes and regulations on cigarette smoking. J Health Econ 1991;10:43-64.

2 Wakefield MA, Chaloupka FJ, Kaufman NJ, et al. Effect of restrictions on smoking at home, at school, and in public places on teenage smoking: cross sectional study. BMJ 2000;321:333-7. 
3 Brownson RC, Hopkins DP, Wakefield MA. Effects of smoking restrictions in the workplace. Annu Rev Public Health 2002;23:333-48.

4 Siegel M, Albers AB, Cheng DM, et al. Effect of local restaurant smoking regulations on progression to established smoking among youths. Tobacco Control 2005; 14:300-6.

5 Hill AB. The environment and disease: association or causation? Proc $R$ Soc Med 1965;58:295-300.

6 Alesci NL, Forster JL, Blaine T. Smoking visibility, perceived acceptability, and frequency in various ocations among youth and adults. Prev Med 2003;36:272-81.

7 Pierce JP, Naquin M, Gilpin E, et al. Smoking initiation in the United States: a role for worksite and college smoking bans. J Ntl Cancer Inst 1991;83:1009-13.
8 Farkas A, Gilpin E, White M, et al. Association between household and workplace smoking restrictions and adolescent smoking. JAMA 2000;284:717-22.

9 Emery S, Gilpin EA, White MM, et al. How adolescents get their cigarettes: implications for policies on access and price. J Ntl Cancer Inst 1999;91:184-6.

10 Harrison PA, Fulkerson JA, Park E. The relative importance of social versus commercial sources in youth access to tobacco, alcohol, and other drugs. Prev Med 2000;31:39-48.

11 Eisenberg ME, Forster JL. Adolescent smoking behavior: measures of social norms. Am J Prev Med 2003;25: 122-8.

12 Bauman KE, Botvin GJ, Botvin EM, et al. Normative expectations and the behavior of significant others: an integration of traditions in research on adolescents' cigarette smoking Psychol Rep 1992;71:568-70.

13 Tworek C, Giovino G, Yang J, et al. Exploring the relationship between cigarette smoking among adolescents and adults in the United States. 2003, Chicago: ImpacTeen Research Paper Series, No 26, University of Illinois, http:// www.impacteen.org/ab_RPNo26_2003.htm.

14 Moore L, Roberts C, Tudor-Smith C. School smoking policies and smoking prevalence among adolescents: multilevel analysis of cross-sectional data from Wales. Tobacco Control 2001;10:117-23.

15 Conley Thomson C, Siegel $M$, et al. Household smoking bans and adolescents' perceived prevalence of smoking and social acceptability of smoking. Prev Med 2005:41:349-56.

\section{EDITORIAL}

\section{The fate of papers rejected from Tobacco Control}

$\mathrm{R}$

ejecting papers is among the hardest tasks that editors must perform. We have strict page limits of 72 pages per issue and typically publish 11 original articles per issue-66 a year. We would like to publish more but our subscriber base and financial situation currently precludes this. Competition to get published is therefore tough. Of the 214 papers submitted to the journal in 2005 (as at 11 August) where decisions have been made, we have rejected 150 $(69.7 \%)$, with 127 (59\% of all decisions) being rejected before review. As authors ourselves, we know how disappointing a rejection can be. But it need not be the end of the road.

In July 2005, we searched the PubMed database for all 286 papers rejected by Tobacco Control between
March 2002 and December 2003. We searched by the first author's name and examined all papers with identical or similar titles to those submitted to Tobacco Control. Ninety (31.4\%) papers had been published in one of 59 different PubMed indexed journals. Preventive Medicine (7), Nicotine and Tobacco Research (6), and the European Journal of Public Health (4) published most. The vast majority $(81 \%)$ of the papers we were unable to publish were published by other international journals, with the remainder finding homes in national or regional journals. In all but six cases, the papers were published in journals with lower impact factors than Tobacco Control's (3.159 in 2004).

In recent months we have been receiving an increasing number of emails where authors ask for a preliminary opinion, before submission, about a paper's likelihood of being accepted. The editors of Tobacco Control perform their editorial duties on a part time basis on top of their professional work. We receive over 400 manuscripts a year, all of which must be read. We simply do not have the time to also read potential or draft manuscripts or to give authors preliminary assessments.

The average number of days we take to reach a first decision has fallen from 37.6 days in 2002 to 13.7 days in 2005. The average number of days from submission to publication has fallen from 214.3 days to 110 days in the same period.

T N Nguyen, S Chapman simonchapman@health.usyd.edu.au 
Passive smoking

\section{Slaying myths about passive smoking} K Jamrozik

\section{The tobacco industry continues to promulgate myths about passive smoking}

t is over 30 years since the appearance of the first English language reports indicating that passive smoking is harmful to the respiratory health of infants and children, ${ }^{12}$ and almost a quarter of a century has elapsed since publication of the first two papers pointing to an increased risk of lung cancer in non-smoking adults who live with smokers. ${ }^{3}{ }^{4}$ The first of these events passed without much discussion but, by the time the second occurred, the tobacco companies were ready with a strategy to oppose what they had been advised was "the most dangerous development yet to the viability of the tobacco industry that has yet occurred". ${ }^{5}$ That strategy went beyond disputing the science to "playing the man"; Hirayama's credentials as a scientist were called into question. Fully nine years later, he was spirited away from the 7th World Conference on Tobacco and Health in Perth, Western Australia, when it seemed that the tobacco companies were about to serve him with a writ. The Director of Action on Smoking and Health (Australia) was unsuccessfully hauled through the courts, and both the editor of this journal and the author of this editorial were served with legal papers designed to prevent them speaking in public about passive smoking $^{6}$ while they were involved in preparation of the second report on the issue from Australia's National Health and Medical Research Council. ${ }^{7}$ That tactic backfired, however, when we called a press conference and described the attempt to gag us.

\section{PERNICIOUS MYTHS}

Such direct confrontations are rare, and it may be that the industry's taste for court action has been curbed by its major setbacks within the legal system of the USA. However, one does not have to be involved in the issue of passive smoking for very long to appreciate that the companies and their fellow travellers have a second, lower profile string to their bow; their persistent promulgation of pernicious myths about passive smoking is a campaign so sustained as to remind one of the "blood libel", that
Jews kill and eat the babes of Gentiles at Passover.

These myths fall into several categories. The first is that passive smoking is, at worst, a nuisance, and that the problem can be solved by a combination of courtesy and ventilation. There is abundant anecdotal evidence that from time to time a polite request that a smoke-free zone be kept that way is greeted with verbal abuse or even the threat of violence, depending on the sobriety of the smoker. Careful calculations by Repace and others show that ventilation is an impractical solution ${ }^{8}$ although it might prove difficult to light a cigarette in the hurricane-like conditions that would need to prevail! In any case, the equipment is expensive to install and run. An official enquiry in Western Australia revealed that the staff of some nightclubs in which smoking was permitted did not even know where to turn on their air conditioning system, let alone how to adjust it in response to particular levels of smoke in the premises. ${ }^{9}$ Thus, the efficacy of courtesy and ventilation is a myth.

The next myths, of impracticality and low compliance, are regularly trotted out when each extension of smoke-free policies is foreshadowed. Time and again these predictions have been proved wrong; indeed, public and employee support for smoke-free policies increase after their introduction, and, given adequate discussion and notice beforehand, compliance with smokefree policies is usually very good. ${ }^{10}$

\section{ECONOMIC IMPACT: A THREE HEADED DRAGON}

The economic impact of smoke-free policies is a three headed dragon. One head anticipates that the introduction of a smoke-free policy will have dire for the hospitality industry. The second speaks within days of the policy being introduced and claims that patronage has slumped. The third waits some weeks and proclaims that the bottom has fallen out of the bottom line. Enter St George, in the guise of Scollo, Lal, Hyland and Glantz whose seminal review $^{11}$ should see this beast in its economic consequences, particularly death throes, with further supportive evidence now emerging from the Republic of Ireland. ${ }^{12}$

The myths mentioned thus far all concern smoke-free policies, but there is a parallel campaign waged against the science underpinning those policies. This tactic, too, draws directly on advice from the Roper Organization. ${ }^{5}$ Again, there are three principal assertions. The most nebulous of these concerns confounding. Like a weak undergraduate student who throws a technical term into an examination answer in the hope that it will attract some marks, the small, although systematic, differences in other aspects of lifestyle between non-smokers from households that include smokers and those from homes that are smoke-free ${ }^{13}$ are held somehow to explain why passive smokers get more lung cancer and heart disease than non-smokers. The exact mathematics are never fully laid bare, but the mud is regularly thrown in the hope that some of it will stick.

\section{MISCLASSIFICATION}

The next line holds, in essence, that at least some smokers are liars. More formally, that misclassification of exposure status, through some active smokers denying their habit, explains much of the apparent risk of passive smoking. Interestingly, of course, this argument implicitly concedes that active smoking is dangerous, something itself long contested by the tobacco industry. Misclassification is considered by Lam et $\mathrm{al}^{14}$ as a possible explanation for their novel finding, reported in this issue of Tobacco Control, that passively exposed active smokers have a significantly increased risk of various upper and lower respiratory tract symptoms compared with those who smoke "in isolation". The findings are based on a cross sectional survey of policemen in Hong Kong, conducted almost 10 years ago. Lam et $a l^{14}$ concede that objective verification of passive smoking among active smokers is difficult but suggest that there is no reason why active smokers with respiratory symptoms should systematically over-report their passive exposure. Presentation of supportive crude odds ratios would have strengthened the case for a true effect, and classifying exposure of policemen on foot patrol according to estimated aggregate daily consumption of cigarettes by their colleagues during working hours is probably an over-simplification. Nevertheless, given the historical period and the prevailing emphasis of the effects of passive smoking on nonsmokers, Lam's results cannot be dismissed out of hand. If replicated, reducing the risk to continuing smokers will 
become another plank in the case for extending smoke-free policies to all workplaces.

\section{RISKS FROM LIGHT SMOKING}

The final charge is that the evident risks associated with passive smoking are implausibly large, given the amount of tobacco smoke that non-smokers inhale. An essential weakness here is that we still do not know for certain which elements of tobacco smoke are responsible for particular problems, notably cardiovascular diseases, in active smokers, and therefore do not know which biomarkers might be relevant in passive smokers. ${ }^{15}$ "Cigarette equivalents" of exposure have been proposed as a surrogate measure, with the detractors regularly claiming that passive smoking is at most equivalent to very light active smoking. Gori, for example, has published an elaborate argument that since epidemiological studies have struggled to demonstrate statistically significant excess risks associated with light active smoking, passive smoking must also carry no hazard. ${ }^{16}$ In a second paper in this issue of the journal, Bjartveit and Tverdal $^{17}$ provide a direct refutation of that proposition through showing, in a large prospective study in Norway, that smokers of 1-4 cigarettes daily more than doubled their chances of dying from ischaemic heart disease and lung cancer, and significantly increased their mortality from all causes over the next 25 years. To paraphrase Glantz, ${ }^{18}$ tobacco smoke is dangerous-period.
The accepted definition of epidemiology speaks not only of what its practitioners study but also "the application of this study to control of health problems". ${ }^{19}$ This direct link between evidence and action is central to epidemiologists' seeming obsession with discounting chance, bias, and confounding as explanations for their results. In creating and promulgating untruths about passive smoking, the tobacco industry has put epidemiologists on their mettle, but the systematic slaying of those myths has only strengthened the case for smoke-free policies, to protect the health of smokers and nonsmokers alike.

Tobacco Control 2005;14:294-295. doi: 10.1136/tc.2005.014092

Correspondence to: Professor Konrad Jamrozik, School of Population Health, University of Queensland, Herston Road, Herston, Queensland 4006, Australia; k.jamrozik@sph. uq.edu.au

\section{REFERENCES}

1 Harlap S, Davies AM. Infant admissions to hospital and maternal smoking. Lancet 1974,i:529-32.

2 Colley JR, Holland WW, Corkhill RT. Influence of passive smoking and parental phlegm on pneumonia and bronchitis in early childhood. Lancet 1974; ii: 1031-4.

3 Hirayama T. Nonsmoking wives of heavy smokers have a higher risk of lung cancer: a study from Japan. BMJ 1981;282:183-5.

4 Trichopoulos D, Kalandidi A, Sparros L, et al. Lung cancer and passive smoking. Int $J$ Cancer 1981;27:1-4.

5 The Roper Organization. A study of public attitudes towards cigarette smoking and the tobacco industry in 1978. Vol 1. Bates No. TIMN0048149 at 0048152.
6 Jamrozik K, Chapman S, Woodward A. How the NHMRC got its fingers burnt. Med J Aust 1997; 167:372-4.

7 NHMRC Working Party. The health effects of passive smoking: a scientific information paper. Canberra: NHMRC, 1997.

8 Repace JL, Lowrey AH. An indoor air quality standard for ambient tobacco smoke based on carcinogenic risk. N Y State J Med 1985;85:381-3.

9 Western Australia Ministry of Health. Report of the Western Australian task force on passive smoking in public places. Appendix 4: report on ventilation issues and risk from exposure to environmental tobacco smoke (ETS). Perth: Ministry of Health, 1997.

10 Miller C, Wakefield M, Kriven S, et al. Evaluation of smoke-free dining in South Australia: support and compliance among the community and restaurateurs. Aust NZ J Publ Health 2002;26:38-44.

11 Scollo M, Lal A, Hyland A, et al. Review of the quality of studies on the economic effects of smoke-free policies on the hospitality industry. Tobacco Control 2003;12:13-20.

12 Central Statistical Office, Ireland. Retail sales index, seasonally adjusted value and volume series, $2000=100$. January, 2005. www.cso.ie.

13 Forastiere F, Mallone S, Lo Presti E, et al. Characteristics of nonsmoking women exposed to spouses who smoke: epidemiologic study on environment and health in women from four Italian areas. Environ Health Perspect 2000; 108: 1171-7.

14 Lam T-H, Ho L-M, Hedley AJ, et al. Environmental tobacco smoke and respiratory ill health in current smokers. Tobacco Control 2005; 14:307-14.

15 Gori GB. Environmental tobacco smoke and coronary heart syndromes: absence of an association. Regulat Toxicol Pharmacol 1995;21:281-95.

16 Glantz S, Parmley WW. Passive smoking and heart disease: mechanisms and risk. JAMA 1995;273:1047-53.

17 Bjartveit K, Tverdal A. Health consequences of smoking 1-4 cigarettes per day. Tobacco Control 2005; 14:315-20.

18 Glantz SA. Smoke-free restaurant ordinances do not affect restaurant business. Period. J Public Health Manag Pract 1999;5:vi-ix.

19 Last JM. A dictionary of epidemiology, $4^{\text {th }}$ ed. Oxford: Oxford University Press, 2001:62. 